\title{
Injury mortality and accessibility to emergency care in Japan: an observational epidemiological study
}

This article was published in the following Dove Press journal:

Open Access Emergency Medicine

17 April 2014

Number of times this article has been viewed

\section{Takashi Nakamura \\ Masanobu Okayama \\ Masakazu Aihara \\ Eiji Kajii}

Center for Community Medicine, Jichi Medical University, Shimotsuke, Tochigi, Japan
Correspondence: Takashi Nakamura Center for Community Medicine, Jichi Medical University, 33 I I-I Yakushiji, Shimotsuke, Tochigi 329-0498, Japan Tel +8I 285587394

Email nakamurata@jichi.ac.jp
Background: Unintentional injury is a major cause of death across the globe. The accessibility to emergency medical services may affect the rate of preventable trauma deaths. The purpose of this study was to analyze the accessibility to emergency medical hospitals in municipalities in Japan and to clarify whether accessibility was associated with the mortality rate attributed to unintentional injuries.

Methods: An observational epidemiological study was conducted in all 1,742 municipalities in Japan. Measurements assessed were population size, accessibility to emergency hospitals, and mortality rates attributed to unintentional injuries. Accessibility of each municipality to their nearest emergency hospital was calculated with a computer simulation using a geographic information system. After calculating demographic statistics and the Gini coefficient of accessibility, multivariate analyses were used to examine the correlation between accessibility time and mortality. Municipalities were divided into six groups according to accessibility time, and we then performed a correlation analysis between accessibility time and mortality using analysis of covariance.

Results: The median time of accessibility to emergency hospitals was 34.5 minutes. The Gini coefficient of accessibility time was 0.410 . A total of 385 municipalities $(23.4 \%)$ had an accessibility time of over 60 minutes. Accessibility was significantly related to mortality (beta coefficient $=0.006 ; P<0.001)$. The mortality rate in municipalities with an accessibility time of $<15$ minutes was lower than that in all other groups. The mortality rate in municipalities with an accessibility time of 15-30 minutes was lower than that in municipalities with an accessibility time of $>30$ minutes, and the mortality rate in municipalities with an accessibility time of 30-45 minutes was lower than that in municipalities with an accessibility time of 60-90 minutes $(P<0.001)$.

Conclusion: The geographical disparities for emergency care accessibility were related to the rate of death by unintentional injury. Improving accessibility to emergency hospitals could help decrease the mortality rate of preventable trauma. Meanwhile, our findings suggest the need for substantially shorter accessibility times to emergency care facilities in many municipalities in Japan.

Keywords: health service accessibility, emergency medical services, wounds and injuries, mortality, geographic information system

\section{Background}

Unintentional injury is one of the leading causes of death. Approximately 5.8 million people worldwide die each year from unintentional injury; this accounts for $10 \%$ of the world's deaths, and the rate continues to increase each year. ${ }^{1}$ According to Vital Statistics of Japan $2012,{ }^{2}$ this is the sixth most frequent cause of death, and in 2012 
over 40,000 people died from unintentional injuries in Japan. Therefore, prevention of death from unintentional injuries is a major concern.

Some deaths due to unintentional injuries are avoidable if accessibility to emergency care is improved. Causes of unintentional injuries include choking, drowning, falling, traffic accidents, fire, and poisoning, but do not include suicide and homicide. ${ }^{2}$ Risk factors for trauma death are classified into three phases (pre-event, event, and postevent) and three factors (human, vehicle, and environment). ${ }^{3}$ Environmental factors contribute to injury mortality more than individual factors; ${ }^{4}$ therefore, improving certain environmental factors is required in order to prevent deaths due to unintentional injuries.

Accessibility to emergency medical care is one such important environmental factor. Accessibility has been defined as access to care, which is the extent to which services are available, can be utilized, deliver needed treatment, and achieve appropriate outcomes. ${ }^{5}$ As of October 2012, there were 8,670 hospitals in Japan. ${ }^{6}$ Of these hospitals, 245 were registered as emergency care hospitals, and rotorcraft aeromedical emergency care was provided in 28 hospitals. There have been few studies investigating the accessibility to emergency care hospitals in Japan. ${ }^{7-9}$ Several studies have explored the relationship between accessibility to emergency care and trauma death. ${ }^{10-13}$ A short out-of-hospital time interval may positively affect trauma patient survival. ${ }^{10}$ Moreover, physician-staffed emergency medical service helicopter systems have saved the lives of many critically ill or severely injured patients. ${ }^{11}$ On the other hand, it has also been reported that accessibility to emergency medical care did not affect trauma mortality. ${ }^{12,13}$ Therefore, the relationship between accessibility to emergency care and trauma mortality has remained ambiguous. Assessments of the accessibility to emergency medical care and its relationship to mortality rates are essential in order to establish an emergency medical care plan.

In addition, previous studies have reported on regional disparity in the number of emergency medical doctors and emergency medical institutions among the 47 prefectures in Japan. ${ }^{8,9}$ These studies have looked at regional gaps demarcated by prefecture or population density, but did not investigate smaller areas. With regard to preventing death from unintentional injuries, a more detailed analysis of accessibility to emergency medical care is required in smaller areas, such as municipalities.

The purpose of this study is to explore accessibility to emergency medical care and to clarify whether this accessibility is associated with the mortality rate attributed to unintentional injuries.

\section{Methods \\ Design and settings}

An observational epidemiological study was conducted in all 1,742 municipalities in Japan. Extracted characteristics were 1) sizes of the overall population and the population aged over 65 years; 2 ) accessibility to the nearest emergency hospital, and 3) the number of deaths and mortality due to unintentional injuries. Data on the population size were extracted from the 2010 census. ${ }^{14}$ The proportion of elderly people in the population was calculated as the number of people in the population aged over 65 years divided by the total population.

Emergency care accessibility defined in this study was a distance from place of residence to the nearest emergency care hospital. Emergency care accessibility was calculated by a computer simulation using a geographic information system. The origin was set to the location of each municipal office. The destination was set to the location of the nearest emergency care hospital. Road network information was provided as "ArcGIS road data". The analysis program was provided as "ArcGIS network analyst". Each program was provided by Esri (Redlands, CA, USA). The output was the amount of time to reach the nearest emergency care hospital by automobile. Deaths due to unintentional injuries were extracted from the Vital Statistics of Japan. ${ }^{15}$ The statistics provided the number of deaths from 2003 to 2007. Mortality was calculated as the number of deaths divided by the total population.

The process of analysis was as follows. Using accessibility time and mortality due to unintentional injuries, we established the Gini coefficient, representative of the distribution of inequality in accessibility times. The Gini coefficient was originally developed in the economic field; however, it has more recently been used in the context of health resources. ${ }^{16,17}$ A Gini coefficient of 0 indicates that the distribution is completely equal, while a Gini coefficient of 1 indicates that the distribution is completely unequal. The subject municipalities were divided into six groups according to accessibility time: those with accessibility times of $<15,15-30,30-45,45-60$, $60-90$, and $>90$ minutes. We then performed a correlation analysis between accessibility time and mortality. Mortalities among each accessibility time group were compared with one another by analysis of variance. After adjusting for age, a linear regression analysis was performed. Accessibility time was set as a dependent variable; mortality was set as 
an independent variable. Mortalities among the accessibility time groups were also compared with one another by analysis of covariance after adjusting for age.

ArcGIS (Esri) was used for geospatial analysis. Stata (StataCorp LP, College Station, TX, USA) was used for statistical analysis. The statistical significance level was set to 0.05 .

\section{Results}

The median accessibility time to the nearest emergency hospital was 34.5 minutes (Table 1). The median incidence of mortality due to unintentional injuries was 1.9 deaths per 1,000 population over the 5-year period. The Gini coefficient of accessibility time was 0.410 . The number of municipalities categorized with an accessibility time of over 60 minutes (including the 60-90 and $>90$ minute groups) was 385 municipalities (23.4\%) (Table 2).

There was a relationship between accessibility time and mortality (Spearman's correlation coefficient $=0.321$, $P<0.001$ ) (Figure 1). Municipalities with longer accessibility times tended to have higher mortality ( $P$ for trend $<0.001$ ).

The results of linear regression analysis showed that accessibility time was a significant predictor of mortality, with a regression coefficient of $0.28(P<0.001)$ and a determinant coefficient of 0.138 . Even after adjusting for age, accessibility time remained a significant predictor of mortality, with a regression coefficient of $0.006(P<0.001)$ and a determinant coefficient of 0.516 .

The mortality rate in municipalities with an accessibility time of $<15$ minutes was the lowest among all accessibility time groups (1.4/1,000 deaths) and increased with greater accessibility time but leveled out at 2.2/1,000 deaths after accessibility times of 45 minutes or more. After adjusting for age, mortality rates among the six accessibility time groups were not the same. The mortality rate in municipalities with an accessibility time $<15$ minutes was lower than that for all

Table I Demographic statistics of municipalities $(\mathrm{N}=\mathrm{I}, 742)$

\begin{tabular}{ll}
\hline & $\begin{array}{l}\text { Median } \\
\text { (interquartile range) }\end{array}$ \\
\hline $\begin{array}{l}\text { Population } \\
\text { Overall population }\end{array}$ & $25,161.5(7,943-65,840)$ \\
Population aged $\geq 65$ years & $6,788.0(2,4 \mid I-I 5,792)$ \\
Proportion of those aged $\geq 65$ years & $27.0(22.4-31.9)$ \\
Accessibility time to an emergency & $34.5(20.4-58.2)$ \\
hospital, minutes & \\
Death due to unintentional injuries & \\
$\quad$ Number of deaths in 5-year period & $52(22-I I 3)$ \\
Mortality per I,000 population in 5-year period & $1.9(I .3-2.5)$ \\
\hline
\end{tabular}

Table 2 Mortality rate and proportion of elderly in population by accessibility time

\begin{tabular}{llll}
\hline Accessibility time & Municipality $^{\mathrm{a}}$ & Mortality $^{\mathrm{b}}$ & Elderly $^{\mathbf{c}}$ \\
\hline$<$ I5 minutes & $246(15.0)$ & 1.4 & 22.6 \\
I5-30 minutes & $465(28.3)$ & 1.7 & 23.9 \\
$30-45$ minutes & $328(19.9)$ & 2.0 & 27.6 \\
$45-60$ minutes & 22 I (I3.4) & 2.2 & 29.2 \\
$60-90$ minutes & $227(13.8)$ & 2.2 & 31.7 \\
$>90$ minutes & $158(9.6)$ & 2.2 & 33.0 \\
\hline
\end{tabular}

Notes: ${ }^{a} n(\%) ; ~{ }^{b}$ the number of deaths per 1,000 in 5 years; ${ }^{c}>65$ years (\%).

other time groups. The mortality rate in municipalities with an accessibility time of 15-30 minutes was lower than that in municipalities with an accessibility time of $\geq 30$ minutes. In addition, the mortality rate in municipalities with an accessibility time of 30-45 minutes was lower than that in municipalities with an accessibility time of 60-90 minutes (Figure 2).

\section{Discussion}

This study showed that 385 municipalities (23.4\%) were not located within 60 minutes of an emergency hospital. According to a US report, ${ }^{18} 1 \%$ of trauma deaths are preventable, and in Japan, it has been reported that up to $40 \%$ of trauma deaths are preventable. ${ }^{19}$ Although emergency care systems in the US and Japan are different, there is the possibility that preventable trauma deaths are more frequent in Japan. According to the Medical Care Act, ${ }^{20}$ all 47 Japanese local governments are responsible for providing emergency medical services to their respective municipalities. The Japanese government has recommended assurance of accessibility within 1 hour. The findings presented here indicate that a quarter of municipalities fail to meet this guideline.

In addition, this study showed that the Gini coefficient of accessibility time to an emergency hospital for municipalities was 0.41 . According to the Japanese Government Redistributed Income Report of 2011, ${ }^{21}$ the Gini coefficient of income after redistribution by taxation was 0.379 . The Gini coefficient of the number of physicians was approximately 0.3 in Japan, USA, and Tanzania. ${ }^{16,17}$ Inequality of emergency medical service and physician distribution are important issues with regard to preventing death by unintentional injuries, and assurance of accessibility is necessary for installation of emergency medical facilities.

This study showed the relationship between accessibility to emergency care and mortality rates from unintentional injuries. A previous study revealed that prehospital delays may worsen the outcome for stroke patients. ${ }^{22}$ In a study exploring whether an eight-minute emergency medical 


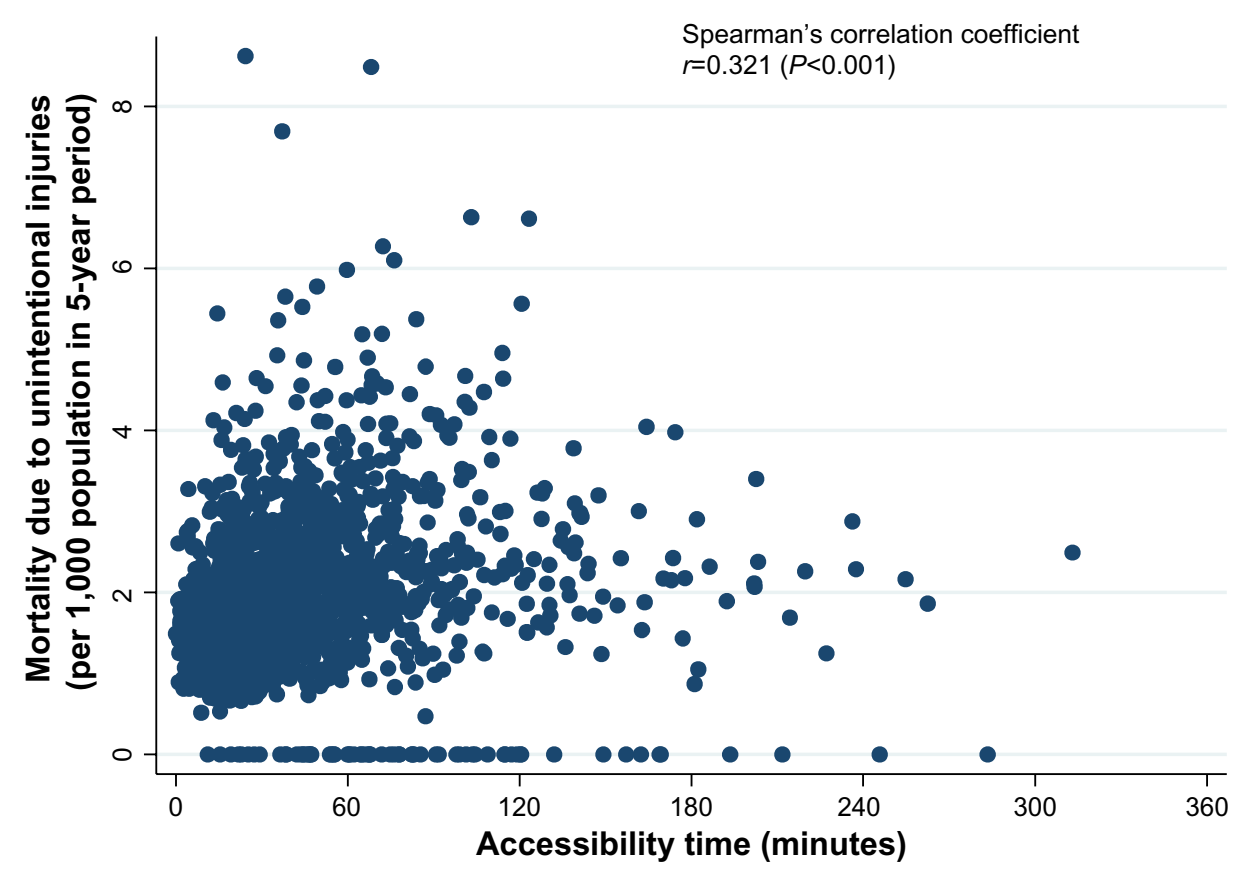

Figure I Correlation between accessibility time and mortality due to unintentional injuries in all municipalities.

services response time was associated with mortality from life-threatening events, mortality rates for response times of $\geq 8$ minutes were significantly higher than those for response times of $<8$ minutes. ${ }^{23}$ The findings in this study are compatible with these previous results. Improving the accessibility to emergency hospitals could help decrease mortality related to unintentional injury.

However, arrangement of emergency hospital locations cannot be decided without considering cost-effectiveness. We observed that mortality rates increased only up to an

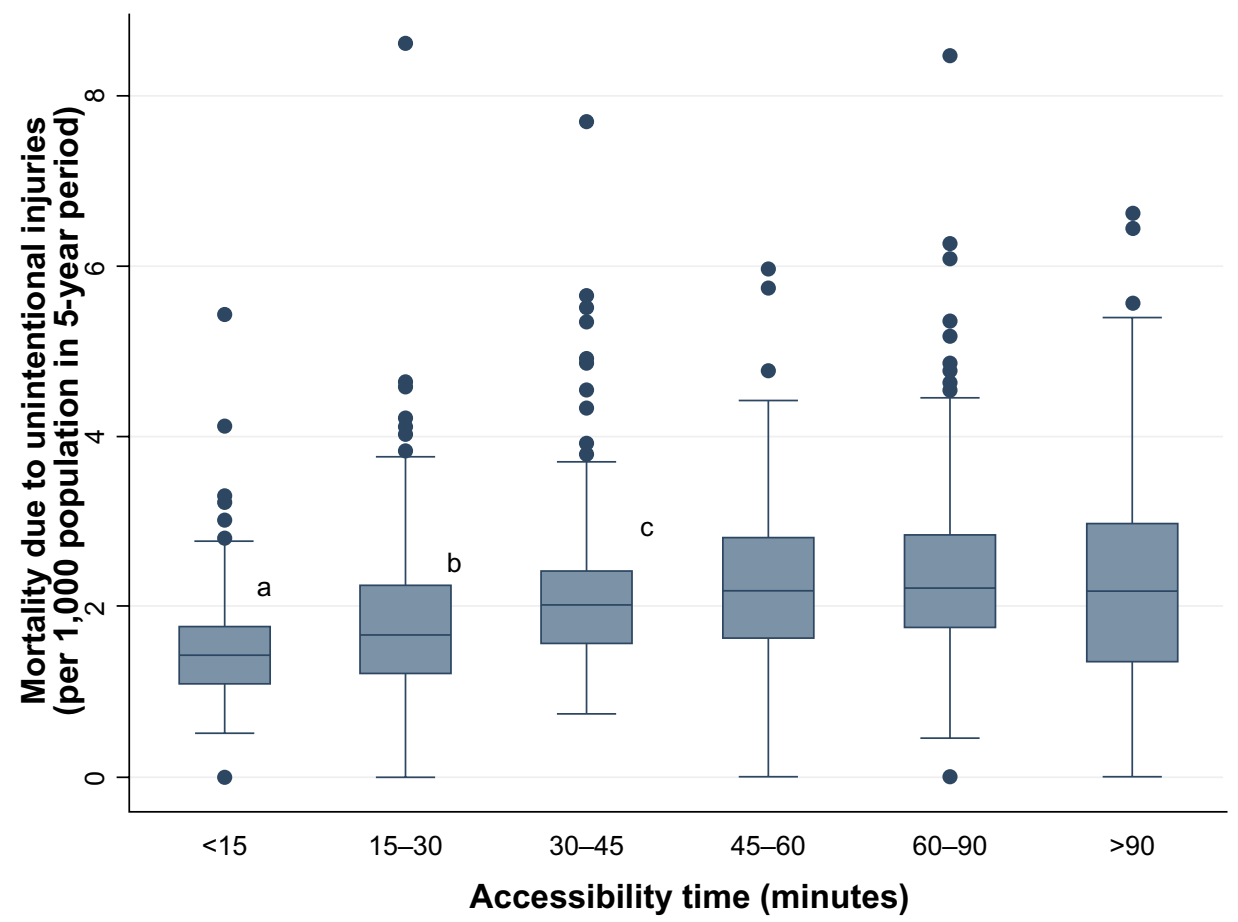

Figure 2 Age-adjusted mortality due to unintentional injuries in municipalities, categorized by accessibility time.

Notes: Box graph for each group: < I5 minutes; 15-30 minutes; 30-45 minutes; 45-60 minutes; 60-90 minutes; $>90$ minutes. aMortality in group I was significantly lower than that in groups 2-6 ( $P<0.05$, analysis of covariance adjusted for age); ${ }^{b}$ mortality in group 2 was significantly lower than that in groups $3-6$ ( $P<0.05$, analysis of covariance adjusted for age); ' $m$ ortality in group 3 was significantly lower than that in group $5(P<0.05$, analysis of covariance adjusted for age). 
accessibility time of 45 minutes. This suggests that emergency hospitals should be located within 45 minutes, at most, from the appropriate municipalities in order to decrease mortality rates. Ensuring a substantially shorter accessibility time for all municipalities would be preferable.

There are several limitations in this study. This research is based on an observational epidemiological design, and we collected data by municipality. We did not deal with individual data, such as age, pattern of injury, severity, transportation measure, treatment, and outcome. Therefore, these research findings should be interpreted with caution. Japanese data about medical care for injuries are accumulated in the Japan Trauma Data Bank. ${ }^{24}$ However, this does not necessarily include data from all medical institutions.

\section{Conclusion}

We observed an obvious disparity in accessibility to emergency care, and geographical disparities for emergency care accessibility were related to unintentional injury mortality. Improving accessibility to emergency hospitals could help to decrease mortality attributed to unintentional injury. Further assessment of the relationship between accessibility and health outcomes is necessary to adequately establish necessary locations of emergency hospitals.

\section{Acknowledgment}

This work was supported by Grant-in-Aid for Scientific Research (A) (23249027) and Grant-in-Aid for Young Scientists (B) (25860468) of the Japan Society for the Promotion of Science.

\section{Disclosure}

The authors report no conflicts of interest in this work.

\section{References}

1. World Health Organization. Injuries and Violence: the Facts. Geneva: World Health Organization; 2010:1. Available from: http://whqlibdoc.who.int/ publications/2010/9789241599375_eng.pdf. Accessed March 5, 2014.

2. http://www.mhlw.go.jp [homepage on the Internet]. Vital statistics of Japan 2012. Tokyo: Statistics and Information Department, Ministry of Health, Labour and Welfare; 2012. Available from: http://www.mhlw. go.jp/toukei/saikin/hw/jinkou/kakutei12/index.html. Accessed March $5,2014$.

3. Haddon W. Advances in the epidemiology of injuries as a basis for public policy. Public Health Rep. 1980;95(5):411-421.

4. Borrell C, Rodriguez M, Ferrando J, et al. Role of individual and contextual effects in injury mortality: new evidence from small area analysis. Inj Prev. 2002;8(4):297-302.

5. Gulliford M, Figueroa-Munoz J, Morgan M, et al. What does 'access to health care' mean? J Health Serv Res Policy. 2002;7(3):186-188.

6. http:/www.mhlw.go.jp [homepage on the Internet]. Survey of Medical Institutions, 2012. Tokyo: Statistics and Information Department, Ministry of Health, Labour and Welfare; 2012. Available from: http://www.mhlw. go.jp/toukei/saikin/hw/iryosd/12/. Accessed March 5, 2014.
7. Kawaguchi $\mathrm{H}$, Kawahara K. Study regarding accessibility to emergency medical care centers: results from the GIS simulation. J Jpn Soc Hosp Adm. 2006;43(1):35-45.

8. Miwa M, Kawaguchi H, Arima H, Kawahara K. The effect of the development of an emergency transfer system on the travel time to tertiary care centres in Japan. Int J Health Geogr. 2006;5:25.

9. Mizuno J, Hanaoka K. Regional differences in the number emergency medical doctors and emergency medical institutions in Japan. $J$ Jpn Assoc Acute Med. 2004;15(11):593-604.

10. Feero S, Hedges JR, Simmons E, Irwin L. Does out-of-hospital EMS time affect trauma survival? Am J Emerg Med. 1995;13(2):133-135.

11. Mashiko K, Matsumoto H, Takuhiro K, et al. A significance of doctor helicopter for establishing trauma care system: from the viewpoint of unexpected death and unexpected survival. J Jpn Soc Aeromed Serv. 2004;5:12-17.

12. Galvagno SM, Thomas S, Stephens C, et al. Helicopter emergency medical services for adults with major trauma. Cochrane Database Syst Rev. 2013;3:CD009228.

13. Newgard CD, Schmicker RH, Hedges JR, et al. Emergency medical services intervals and survival in trauma: assessment of the "golden hour" in a North American prospective cohort. Ann Emerg Med. 2010;55(3): 235-246. e4.

14. Statistics Bureau of Japan, Ministry of Internal Affairs and Communications. The 2010 Population Census of Japan. Tokyo: Statistics Center; 2012.

15. Ministry of Health, Labour and Welfare Japan: Vital Statistics by health center and municipal, 2003-2007. Health and Welfare Statistics Association, 2009

16. Matsumoto M, Inoue K, Bowman R, Noguchi S, Toyokawa S, Kajii E. Geographical distributions of physicians in Japan and US: impact of healthcare system on physician dispersal pattern. Health Policy. 2010;96(3):255-261.

17. Munga MA, Mæstad O. Measuring inequalities in the distribution of health workers: the case of Tanzania. Hum Resour Health. 2009;7(1):4.

18. Acosta JA, Yang JC, Winchell RJ, et al. Lethal injuries and time to death in a level I trauma center. $J$ Am Coll Surg. 1998;186(5):528-533.

19. Otomo Y, Hemmi H, Honma M, et al. Quality of trauma care in each hospital should be evaluated for deciding receiving hospital. J Jpn Assoc Surg Trauma. 2002;16:319-323.

20. japaneselawtranslation.go.jp [website on the Internet]. Medical Care Act (Act 205 of 1948, Japan), Section 2, Medical Care Plans; V. Ensuring the Medical Care Delivery System. http://www.japaneselawtranslation.go.jp/law/detail/?id $=2138 \& v m=04 \&$ re $=02$. Accessed March 6, 2014.

21. Director-General for Policy Planning and Evaluation, Ministry of Health, Labour and Welfare (Japan). [Survey on the Redistribution of Income]. Tokyo: Ministry of Health, Labour and Welfare; 2011. Available from: http://www.mhlw.go.jp/file/04-Houdouhappyou12605000-Seisakutoukatsukan-Seisakuhyoukakanshitsu/h23hou_1. pdf. Japanese. Accessed March 5, 2014.

22. Ohwaki K, Watanabe T, Shinohara T, Nakagomi T, Yano E. Relationship between time from ambulance call to arrival at emergency center and level of consciousness at admission in severe stroke patients. Prehosp Disaster Med. 2013;28(1):39-42.

23. Blanchard IE, Doig CJ, Hagel BE, et al. Emergency medical services response time and mortality in an urban setting. Prehosp Emerg Care. 2012;16(1):142-151.

24. Japan Trauma Care and Research [website on the Internet]. Japan Trauma Data Bank Report 2013 (2008-2012). Available from: http:// www.jtcr-jatec.org/traumabank/dataroom/data/JTDB2013e.pdf. Accessed March 25, 2014. 
Open Access Emergency Medicine

Dovepress

\section{Publish your work in this journal}

Open Access Emergency Medicine is an international, peer-reviewed, open access journal publishing original research, reports, editorials, reviews and commentaries on all aspects of emergency medicine. The manuscript management system is completely online and includes a very quick and fair peer-review system, which is all easy to use.

from published authors.

Submit your manuscript here: http://www.dovepress.com/open-access-emergency-medicine-journal 